\title{
ALEGORÍAS DE LA ESCRITURA: DEL SIGNO AL SÍMBOLO EN LA POESÍA DE ANDRÉS SÁNCHEZ ROBAYNA
}

\author{
ALLEGORIES OF WRITING: FROM SIGN TO SIMBOL \\ IN ANDRÉS SÁNCHEZ ROBAYNA'S POETRY
}

\author{
Pablo ROMERO VELASCO \\ Universidad de Valladolid \\ pablo.romero.velasco@alumnos.uva.es
}

Resumen: La poesía de Andrés Sánchez Robayna siempre ha estado gobernada por dos ideas: la metáfora del mundo como texto y la concepción mística de la poesía como vehículo de conocimiento trascendente. Partimos de estos dos principios para estudiar los usos retóricos de los poemas del autor y precisar la concepción del lenguaje que se ofrece en ellos; concretamente, su capacidad para crear, recrear o representar experiencias trascendentales. Recurriendo a ciertas consideraciones teóricas acerca del lenguaje simbólico y su relación con la alegoría, se describe la evolución de su obra como el paso de una poesía metalingüística a un lenguaje simbólico.

Palabras clave: Andrés Sánchez Robayna. Estética del silencio. Símbolo. Alegoría. Poesía mística.

Abstract: Andrés Sánchez Robayna's poetry has always been ruled by two poetic principles: the world-as-text metaphor and the mystic notion of poetry as a means of reaching trascendental knowledge. Guided by these principles, this paper studies the rhetorical mechanisms in Robayna's poems to precise the vision of poetic language's nature showed in them 
- specifacilly, its capicity to create, re-create and/or represent trascendent experiences. We will appeal to some theoretical remarks on symbolic language and its relationship with allegory to describe the evolution of Robayna's evolution as the passage from a metalinguistic poetry to a symbolic one.

Key Words: Andrés Sánchez Robayna, Aesthetics of silence. Symbol. Allegory. Mystic Poetry.

\section{INTRODUCCIÓN}

La poesía de Andrés Sánchez Robayna (Las Palmas de Gran Canaria, 1952) se enmarca sin dificultades en la línea de una concepción de la poesía como vehículo de conocimiento trascendente: Robayna concibe lo poético como un abrirse a la palabra, "a un recibir infinito" donde "el signo llega entonces a ser iluminador y a anunciar un conocimiento de lo impensable" (Sánchez Robayna, 2004: 430). La palabra poética, pues

tal vez no sea, en un sentido estricto, una palabra de conocimiento (pues también, y en no menor medida, lo es de no-conocimiento); ni su sentido venga dado, en gran parte, por el silencio; ni la defina, únicamente, ser expresión de interioridad [...] La poesía tiende a situarse en medio de esos planos mediante un trabajo en el que los valores semánticos, nunca perdidos, restablecen la posibilidad de descubrir el mundo (2004: 431-432).

Su obra se consideró en su momento adscrita a la estética del silencio $^{1}$ surgida en los años setenta y ochenta al calor del magisterio de José Ángel Valente, quien había traducido a la práctica poética las ideas de María Zambrano² (Villena, 2000: 41); alimentada también por los

1. Es de referencia obligada la tesis doctoral de la también poeta Amparo Amorós (1992) sobre la tendencia que nos ocupa. Cuenta con una amplia y utilísima introducción donde estudia los antecedentes de esta tendencia. Muy provechoso también es el artículo del año 1982 y que sirve de base a la tesis.

2. Las obras completas de María Zambrano, como señala Amparo Amorós, no se publicaron en España hasta los años setenta (Amorós, 1982: 19). 
presupuestos formales de la poesía pura y la influencia de poetas europeos como Mallarmé, Celan, Wallace Stevens o Ungaretti - influencias a las que en el caso de nuestro poeta se sumarían, entre otras, las de Francis Ponge, Haroldo de Campos o el pintor Tàpies.

Lo cierto es que, en puridad, en esta tendencia sólo podemos incluir sus tres primeros libros, Clima (1978), Tinta (1981) y La roca (1986). La crítica ha coincidido, con la aprobación del autor, en establecer tres etapas en la obra publicada hasta ahora: un primer ciclo de 1970 a 1985, con estos tres libros; otro de 1985 a 1999, con Palmas sobre la losa fría (1989), Fuego blanco (1992) y Sobre una piedra extrema (1995); y una última etapa, todavía abierta, en la que ha publicado El libro, tras la duna (2002) y La sombra y la apariencia (2010) (Ruiz Casanova, 2011: 32).

Nosotros nos centraremos en estos dos primeros ciclos con el objetivo de estudiar el lenguaje poético de Sánchez Robayna, confrontando su poética explícita con el estudio pormenorizado de algunos poemas de estos seis libros, analizando el comportamiento de su lenguaje y su retórica y ahondando, en fin, en la concepción del lenguaje literario del poeta canario, de sus posibilidades expresivas, de su relación con la realidad y la capacidad de captar experiencias trascendentales. Nuestro objetivo es describir la auténtica transformación de una etapa a otra como el paso de una poesía eminentemente metalingüística a un lenguaje simbólico relacionado con lo sagrado.

\section{EL MUNDO COMO TEXTO}

Como indica Laura López Fernández, el esencialismo en Sánchez Robayna, como el de autores semejantes, "se basa en la provisionalidad del signo como esencia. [...] sitúa lo transcendente dentro del nivel lingüístico del poema" (López Fernández, 2000: 172-173). Es decir, la poesía de Andrés Sánchez Robayna tiene un alto componente metalingüístico, pues existe en él "el deseo de poner su mito a prueba" (Terry, 2000: 87-88), ya que su imagen del mundo tiene que ser construida por un lenguaje que es, para todo poeta moderno, sumamente inestable; la referencialidad en sus poemas no se suspende, sino que se filtra a través del lenguaje y se recrea mediante un patrón diferente (Terry, 2000: 87-88).

Este aspecto metalingüístico se relaciona con la idea, central para la poética de Robayna, del "mundo como texto", en la que insiste en varios 
lugares. Es esta una metáfora antiquísima según la cual "el mundo es un texto, una escritura, que los hombres desciframos o leemos. Las casas, los árboles, los ríos, los hombres, son los renglones de una escritura, la escritura de la naturaleza" (Sánchez Robayna, 1993: 43). O, dicho con las palabras, varias veces citadas por Robayna, de Francis Ponge,

podría decirse que la naturaleza entera, incluidos los hombres, no es más que una escritura; pero una escritura de un cierto género; una escritura no-significativa, no referida a ningún sistema de significación; se trata de un universo indefinido: hablando en propiedad, inmenso, sin medida (Francis Ponge, cit. en Sánchez Robayna, 1993: 4344).

Estas líneas las recoge Robayna al comienzo de un estudio, "Góngora y el texto del mundo", en que aplica la metáfora del mundo como texto a la poesía del autor barroco; un artículo donde desarrolla esta idea in extenso y que viene a dar la clave de toda esta primera etapa de su poesía. En sus Soledades, Góngora habla de la naturaleza como texto, pero al mismo tiempo habla de la escritura del poema en una especie de metalenguaje: "la realidad aparece, en efecto, en perfecta superposición respecto a su relato. Isomorfía o metáfora absoluta. Intercambiabilidad de realidad y escritura, de texto y mundo" (1993:46). Góngora, según Robayna, concibe la poesía como un texto que imita o traduce el texto que es el mundo, y cita unas palabras de Umberto Eco sobre la poética barroca que bien podrían estar refiriéndose al autor canario:

La poética del asombro, del ingenio, de la metáfora, tiende en el fondo, más allá de su apariencia bizantina, a establecer esta tarea inventora del hombre nuevo que ve en la obra de arte no un objeto fundado en relaciones evidentes para gozarlo como hermoso, sino un misterio a investigar, una tarea a perseguir, un estímulo a la vivacidad de la imaginación (Eco, cit. en Sánchez Robayna, 1993:54).

Según Robayna, siguiendo a Ortega, lo que hace Góngora - y él mismo - es buscar una transcripción poética de la realidad; no reflejarla, 
sino transponerla en una realidad autónoma pero paralela; y para acercar realidad y escritura, tiene que pensar aquella en los términos de esta (1993: 54). Así aparece el libro -la escritura- como un suplemento (según el término de Derrida) de la naturaleza, que la completa, "la dota de un reflejo, la sitúa ante el espejo [...] el libro es la naturaleza pensándose a sí misma, viéndose; es la naturaleza que se escribe y se lee a sí misma" (Sánchez Robayna, 1993: 55-56).

En otros artículos Robayna concibe, en la línea de Derrida y otros, como él mismo señala, la lectura como una escritura y viceversa. Y, si el mundo es un texto, el acto de escribir sería un leer esa escritura que es la naturaleza:

Hay, así, el lenguaje de los "objetos conmovedores: los sonidos significativos y articulados" y hay, de otra parte, el tejido, el texto de la naturaleza o el mundo como lenguaje. [...] Escribir, es entonces, un leer en la escritura de la naturaleza; y leer, paralelamente, un escribir o reescribir la escritura que antes ha sido una lectura de la naturaleza o del mundo (Sánchez Robayna, 1985: 122-123).

En esta polaridad que iguala realidad y texto, lectura y escritura, quisiéramos hacer hincapié no en el polo de lectura de lo real sino en el de su escritura. Insistamos en esta idea, porque es fundamental para nuestra argumentación: Sánchez Robayna expone que Góngora no refleja el mundo, sino que lo traduce en una realidad paralela: para hacer equivaler realidad y escritura, piensa aquella según rasgos de ésta, la transforma. El poema no dice sino que hace, no describe una semejanza (la realidad es como un texto), sino que la produce: la realidad se hace texto. Los críticos, en general, lo confirman. Así dice Rodríguez Padrón sobre Clima:

Poesía es conocimiento. Pero conocimiento que va más allá de las superficies, que disuelve límites y que configura el mundo como una sola realidad: la que revela la palabra que lo dice. Realidad no es, en la poesía de Andrés Sánchez Robayna, lo mirado, sino lo dicho; es más, por decirla, la realidad se inaugura (Rodríguez Padrón, 1979: 24). 
La realidad es dicha, transformada por la visión poética. Pero todo lo que puede haber de inestable, de ambiguo, de hermético, de opresivo o doloroso en este libro es achacado a la esencia de lo real; la escritura, en todo caso, anula las dificultades al purificar la visión. Así lo asegura el mismo crítico, hablando sobre Tinta: "Estos poemas, pues, son un diálogo entre vitalidad y fijación; resuelven la contradicción surgida en el vértice de una escritura que es, simultáneamente, estática y dinámica", y la "reiterada inestabilidad" de lo real, "esta peligrosa concreción de una evidencia que contiene su propia negación" se anula con el ritmo y la precisión de la construcción poemática (Rodríguez Padrón, 1981: 3). Sánchez Robayna se sirve de un vocabulario mínimo al que somete a constantes modulaciones y combinaciones, y "al incluir tal léxico en una determinada sintaxis, al someterlo a nuevas modulaciones, a relaciones inesperadas; al romper voluntariamente los nexos posibles, las palabras retoman su poder inaugural: nombre y verbo alumbran el instante misterioso, inefable, de la creación” (Rodríguez Padrón, 1981: 3).

Parece haber, pues, un perfecto trasvase de la realidad al lenguaje; la realidad que el lenguaje inaugura nace sin mayores dificultades. Por eso quizá nos resulten más interesante para nuestra argumentación las consideraciones de Arthur Terry, quien, si bien superficialmente -obligado por lo breve de su panorámica-, insiste en la dimensión metalingüística de esta operación del lenguaje poético. El crítico destaca la reiterada presencia del vocablo "signo" en la poesía de Sánchez Robayna. Estos signos a que se refiere el poeta son, en primera instancia, "los mismos objetos que parecen resumir, o concentrar, la experiencia de vivir en un lugar determinado, los componentes del mito insular" (Terry, 2000: 89). Pero, obviamente, lo que está presente en el poema no son los objetos, sino sus nombres, y como estos "no se dejan leer de una manera sencilla", "cualquier sentido ha de buscarse dentro del mismo signo: a diferencia del símbolo, que siempre mira más allá de sí mismo, el signo es autónomo, de modo que cualquier intento de extraer sentido de él ha de tener lugar en el mismo interior de la palabra". Por ello, los poemas de Sánchez Robayna tienden "a desviarse del mismo objeto" a sus nombres (Terry, 2000: 89-91): la experimentación lingüística es eso: estrictamente lingüística.

Es en Tinta donde la metáfora del mundo como texto se hace explícita. Los elementos del paisaje canario se vuelven escritura, líneas, renglones, puntuación, páginas en blanco, leídas y des-leídas por la mirada: 
La roca (la noche) late entre olas altas noctivaga memoria en los bordes de piedra la memoria escribió signos de arena ya borrados las nubes escribieron su texto contra el cielo en que yace la escritura que el agua transcribe en olas altas donde late la roca (la noche) en su bajorrelieve $[\text { Tinta, 110 }]^{4}$.

el cielo negro y su escritura blanca cerrados sobre el paseo de palmeras se vierten se tienden se escriben la arboleda tamiza el ruido de los claxons lejanos apagado sonido respuesta escrita en el tejido de la ventisca hendedura invisible

otro el texto que desconstruye y se agita y se enarcacerca del rumor de los tilos

la noche-

la tinta $-[\text { Tinta, } 112]^{5}$.

Ejemplos como estos abarcan casi todo el libro. Vemos cómo, en el primer poema, arena, cielo y mar son las páginas en blanco donde piedras, nubes y olas hacen las veces de signos de escritura. Pero lo que está explícito en este libro también lo encontramos en el anterior, Clima.

Así lo comprobamos, por ejemplo, en el poema "Médano" [24-26], donde encontramos una cita del brasileño Haroldo de Campos, "sintaxe e dunas" que ya nos pone sobre la pista. Los médanos ("duna" y también "montón de arena casi a flor de agua, en un paraje en que el mar tiene poco fondo", nos informa el DRAE) que dan nombre al poema hacen las veces de "signos" sobre la página del mar ("Dos o tres rocas / en el mar de las islas. / Son los signos, / los médanos;"); los espacios entre las ramas ("el vacio entre una y otra rama/ al sol;") remedan los espacios entre una palabra y otra, y la rama misma, por su delgadez, da la sensación de ser

3. De aquí en adelante, salvo que se indique lo contrario, las cursivas son nuestras.

4. Citamos todos los poemas por la edición de 2004 de su poesía reunida En el cuerpo del mundo (Sánchez Robayna, 2004). Entre corchetes indicamos el título del poema, el libro al que pertenece y la página que corresponde a dicha edición de 2004.

5. Para un análisis detallado de este poema, así como de los demás poemas en prosa que componen Tinta, puede consultarse el artículo de Mata Buil (2014). También Jiménez Arribas (2004) dedica un capítulo de su tesis sobre el poema en prosa a este libro. 
el trazo de una escritura. En los poemas de Clima, la mirada (la escritura) centra los objetos (los signos) sobre las superficies paisajísticas; la misma factura de los poemas se corresponde con esta idea: versos cortos, frases nominales aisladas, sin conexiones sintácticas, desperdigados por el borde de la página, de manera radical en los dos últimos poemas del libro.

Comprobamos en este poema también la frecuente presencia en la primera poesía de Sánchez Robayna no tanto de los objetos como de la "huella" ("Entre las huellas de la duna,") que dejan sobre las superficies (mar, arena, cielo), la "sombra" que proyectan con ayuda de la luz estival ("cuando tu cuerpo tiene la misma ligereza / de frescas sombras sobre / el sonido del mar."; "La luz creó la roca, / saltó sobre las dunas / [...] Entre el viento y la roca, una rama, / fija como su sombra sobre el mar estival."). Es fácil seguir este rastro de sombras: en un poema de Tinta leemos "En la terraza del sol quieto y vacío una hoja dibuja su sombra y ésta le devuelve su presencia" ["El vaso de agua", 100], y en un poema de La roca la sombra de un bañista en el fondo de la piscina remite al cuerpo que la proyecta del mismo modo que la luz fija la sombra de las nubes en el suelo, dando cuerpo a lo que no tiene contorno (encontramos unas imágenes parecidas en el poema "Madrigal", incluido en Tinta):

no en roca viva: entre granito

tallados ángulos de piscina

la sombra al fondo en el mosaico

dibuja arriba la figura

lejos las nubes sin contorno

van deslizándose sin prisa

en la luz ciega de los bordes

lábil la luz la sombra fija

así su cuerpo escrito huye

tallada así la luz se abisma ["Para la sombra de un bañista", $133]$.

Observemos que no es el cuerpo lo que "dibuja” su sombra, sino al 
revés, la huella le da forma al objeto, contornos, presencia. Hay en esta primera poesía cierta obsesión por los contornos, por los bordes de los objetos, su forma:

El borde acuña su fracción de nada el centro acude a cada punto que se reparte cuanto cubre sobre su cubo vacuo la lengua reposa como el pie en una estera soleada cuadrado negro sólo el borde del pie sobre la estera inclinado leído en el dado negro del poema ["Cuadrado negro", Tinta, 114].

negro tranquilo de la forma:

las lisas aristas fluyeron

calma fluida lisa negra

soledad entera de la forma [“A una roca", La roca, 145].

Domínguez Rey describe este proceso para La roca en unos términos aplicables a los dos libros anteriores: "Un haz de luz, vertical u oblicuo, incide en un plano y genera los contornos de los objetos, cuyas sombras sirven, a la par, de puntos diferenciales en la uniforme superficie del espacio" (Domínguez Rey, 1985: 5). La mirada no se centra en el objeto, sino en su sombra, esta es el trazo dibujado sobre el papel del mar o del cielo $^{6}$. No es difícil advertir el carácter semiótico de esta operación en la que una forma remite a un contenido, pero insistimos: es la forma la que configura al objeto, no al revés.

En "Fragmentos nocturnos" [Clima, 28-29] encontramos un texto metapoético: asistimos a una escena nocturna en la que el yo está escribiendo mientras de fuera le llega el sonido de las ramas de los pinos agitadas por el viento. En líneas generales, el poema establece y explora una relación interior (mente) - exterior (noche) ejecutada en la escritura. En el primer fragmento se nos describe no la realidad exterior, sino el espacio mental en el que el poeta está configurando el espacio nocturno ("La idea de la luna, / el espacio sombrío de dos / laderas en la mente/ [...] / (dije)"), confundido con el espacio (físico) de la escritura: "entre los

6. Robayna cita como epígrafe a la segunda sección de Clima un verso de Mallarmé, "la pièce écrite au folio du ciel", y para una sección de Tinta, otro de Góngora: "en el papel diáfano del cielo". 
bordes de la hoja / -líneas del mar cercano".

El segundo fragmento presenta una medida estructura en cierto modo simétrica de cinco estrofas en las que sí se nos describe el espacio exterior mediante las sensaciones que el yo recibe - principalmente, el "rumor de los pinos". La misma descripción con los mismos elementos (el aire agita las ramas en la noche) se repite en las cuatro primeras estrofas, pero con variantes sintácticas y en las figuras: en la primera el aire está implícito en el "rumor de los pinos" y las ramas (de nuevo, su figura) dividen organizan, configuran- el espacio nocturno; en la segunda es el aire el que "divide" las hojas (no las ramas) identificadas como "pensamientos / que la noche dispone"; en la cuarta el aire de nuevo "agita" las ramas, que por efecto de este movimiento parecen "vivas". Es la tercera estrofa ("Noche de dos mitades / azules en la mente. / El pensamiento las recorre") la que hace de eje del fragmento, organizando sus dos "mitades" simétricas, y nos descubre el sentido del poema: el paisaje no es un paisaje objetivo sino mental, recorrido por el pensamiento, que lo dispone, "divide", ordena y reordena, jerarquiza los elementos y sus relaciones, transformando no tanto la visión objetiva como la configuración poemática. Así, en la última y quinta estrofa la mente ocupa el lugar que le corresponde y "cae y divide / el oleaje de los pinos". Esta última metáfora, en la que el sonido de las ramas es equiparado al sonido del oleaje marino, es clave: la huella de los pinos, su sonido, su significante, si seguimos con nuestra argumentación, es transformado en significante de otro contenido, el mar; dicho de otro modo, el mar es traído a la mente por su significante. De este modo vemos reforzada nuestra argumentación acerca del juego de los significantes de la poesía de Sánchez Robayna.

Atendamos a un último poema de Clima, "Cifra del arrecife" [74-76], cuyo título "parece indicar que se trata de un poema [...] que ejemplifica lo que el lenguaje -cierto tipo de lenguaje- es capaz de hacer" (Terry, 2000: 97). En el poema, el yo -expresado como "pensamiento"- se nos presenta contemplando un arrecife/acantilado desde una barca. Desde esta situación el poema expresa una "prueba del ser" (Terry, 2000: 100), un intento de la conciencia de "ser con el paisaje".

El yo, "buque ignoto / pensamiento cerrado en una barca / crispada por solo" cubre con su conciencia el paisaje desértico y vacío ("cubre / precipitadamente / [...] / un seco roquedal que el viento envuelve"). Su mirada encuentra una formación rocosa, "algo como una puerta sellada", 
"medida negra": umbral que promete el paso a una realidad trascendente, a un "negro pensamiento sin pensar", "puerta oscura a ningún pensamiento". La conciencia poética busca descifrar este umbral, "suscitado por las olas deletreadas / bajo el informe ritmo"; pero frente al preciso "deletrear" del mar, la puerta sólo es "pronunciada" - paradójicamente, mientras que este deletrear se da "bajo el informe ritmo" del mar, la puerta ha sido "esculpida por miles de soles", sugiriendo un mayor rigor en sus formas.

El poema se desarrolla en un ambiente opresivo, "de plena / cerrazón”, crispado, "desértico", "plomizo", donde la luz del sol, más que favorecer obstruye la visión y el "pensar hollado / por un sol que tampoco me ignora". En este ambiente de "pura acidia del día / encerrado en su ritmo de abismos", la puerta se presenta inaccesible al pensamiento, siendo un "puro estar de precipicio". Por eso, el ser sólo puede ser "oscuro", reflejo "del oleaje de la luz y los chorros / del agua encrespada" y tornar "su ser en ser desierto".

El pensamiento se pierde "en los intersticios de las taparuchas", se abisma en la desierta acidia del paisaje. Choca incesantemente contra el "puro estar de precipicio" del acantilado. "Precipicio" es aquí otro vocablo clave. El precipicio es la forma misma del acantilado, forma que el pensamiento toma y, como en otros poemas, lo transforma en palabra, en significante: el "precipicio" no es el acantilado, sino una transformación léxica del adverbio "precipitadamente" que hemos encontrado al comienzo del texto. "Precipicio", así, es la forma no del paisaje sino del poema, del pensamiento que lo configura: es el pensamiento el que se precipita en ritmos abismados e intersticios en blanco dispuestos tipográficamente en un uso muy mallarmeano del blanco de la página. La lectura muestra que las predicaciones atribuidas a la "puerta" son obra de la conciencia y en última instancia remiten a ella: desde el principio no existe tal puerta, sino "algo como una puerta", y este algo que en un principio se nos presenta como "esculpida por miles de soles"; más adelante leemos que es el yo quien la cincela ("picapedrero ignoto esculpo nada / de sol / como él golpeo un desierto") y que el "puro precipicio / colmado de su estancia" no está sino "detrás / de la sílaba negra": la palabra, el pensamiento.

Así es como opera el lenguaje de Sánchez Robayna: toma de un objeto sus formas más esenciales, el precipicio en este caso, y las convierte en signo del poema, juega no con ellas sino con su palabra, su significante "deletreado", al que somete a una serie de transformaciones que sólo 
acaban refiriéndose a sí mismas ("oscuro / el ser que se responde // oscuro / ser como un ritmo volcado"). El mismo título, "Cifra del arrecife", es expresivo de esta operación: toma de la palabra "arrecife" su forma fónica para transformarla en eso, en una "cifra", no en su acepción de emblema, sino de código hermético: un lenguaje que no descifra, sino que "cifra", que no desvela sino que oculta. La conciencia poética se extiende sobre el paisaje, lo reduce a sus formas significantes, para luego cerrarse sobre sí misma.

El juego fónico se intensifica en Tinta, y un buen ejemplo de ello es el poema "Sistema" [103], inspirado por un cuadro de Mark Rothko, "Ochre and Red on Red". El motivo principal es el paso constante entre "hoja roja" y "hora roja"; lo interesante del poema es que explicita el proceso de transformación: empieza como una visión más o menos sinestésica ${ }^{7}$ ("Sobre la hoja ved el otoño. La hoja roja en que descansa el otoño, vedla": el rojo viene del cuadro de Rothko, y el otoño está sugerido por el color ocre del mismo) pero pronto la atención se centra, explícitamente, en el significante de la palabra "hoja" escrita:

Diríase que la hoja roja descansa sobre una hora indecisa. La hora indecisa como el lecho en que la hoja descansa. Digo: Diríase que la hoja roja descansa sobre una hora indecisa; lo escribo y lo leo. Y lo desleo: preveo que hoja $y$ hora pueden asociarse de otra forma, establecer una corriente: ved la hora como una hoja, en su descanso de otoño [La redonda es de Sánchez Robayna].

Como apunta Terry, "aquí la hoja es puramente verbal, no corresponde a nada fuera del poema" (2000: 104); también la "hora" es sólo verbal, sin que podamos atribuirle ningún sentido temporal: su presencia sólo es traída por el parecido de su significante a los de "hoja" y "roja". Y como se dice en el mismo poema, esta conexión sólo se da en la mente del poeta en el proceso de escritura. El "diríase" remite a otros poemas de Clima ("Diríase que el mar/ moviera el aire entre las cañas" [Clima, 41], por ejemplo) que indica su naturaleza puramente especulativa.

7. Para un análisis de las relaciones sinestésicas en Tinta, remitimos al artículo ya citado de Mata Buil (2014) 


\section{EL CAMINO A LA PALABRA SAGRADA}

Este es, a grandes rasgos, el sentido de la experimentación lingüística en la primera poesía de Sánchez Robayna. En La roca, esta experimentación, fónica sobre todo, el concretismo de sus imágenes y el adelgazamiento retórico y métrico alcanza un punto de no retorno, como vemos, por ejemplo, en "Retama" [La roca, 155-158]:

retama
tú que
alzas
albor
no
temes
sombra sobre
tu
ramo
de claridad
dime
al oído
di-
le
tu solo
silencio
le-
vantado del
viento.

Pero, como el mismo autor percibe, así como gran parte de la crítica, este es un punto muerto. Comenta Rodríguez Padrón en una reseña al libro:

Es evidente que una poesía tan radical, con tanto afán perfeccionista, va a tener sus servidumbres; y el escritor debe estar muy atento para no caer en los helados rigores de una palabra que se adensa y se despoja hasta extremos 
muy peligrosos. La Roca es, pues, un libro final. Y está bien que así sea. [...]. No ignora nuestro poeta que una precisión extremada y constante, una distancia excesiva y su insistencia en lo conceptual pueden derivar, si se abandona a las sugestiones de la forma o a las veleidades de la estética, en una escritura cerrada sobre sí misma, y cada vez más pobre en sugerencias. [...]

Pues bien, esas "prisiones de la luz" [refiriéndose a un verso del libro] son - a mi entender - el límite a que ha llegado la poesía de Andrés Sánchez Robayna; el punto de no retorno de esa escritura. A partir de aquí, debe reemprender un nuevo camino; aunque para iniciar este nuevo itinerario debe romper con los vicios adquiridos, contradecir sus fórmulas, poner en duda sus fidelidades, incluso desde dentro de esa misma poesía, desarrollando las conquistas hasta ahora alcanzadas. Pero no insistiendo en volverse sobre sí misma y continuar indefinidamente la contemplación de su propia imagen [...] (Rodríguez Padrón, cit. en Amorós, 1992: 576-577).

El mismo Sánchez Robayna, creemos que en una muestra de autocrítica, advierte en "Deseo, imagen, lugar de la palabra" contra la "idolatría" de la palabra, contra que esa atención a la materialidad del lenguaje se convierta en "una seducción que corre una y otra vez, en la poesía, el riesgo de volverse autosuficiente [...] la escritura avanza a veces sobre el borde de la sonoridad verbal hasta recibir la severa amenaza de un sordo nihilismo, de una cerrada aniquilación del significado" (Sánchez Robayna, 2004: 431).

Es en este artículo, aparecido en 1995 y posteriormente recogido como epílogo en la reunión de su poesía de 2004, y que citábamos al comienzo de este artículo, donde más diáfanamente expone su nueva concepción poética. Allí proponía la palabra poética, recordemos, como un abrirse al infinito y las realidades últimas mediante la carnalidad de la palabra, que es un recordar la materialidad del mundo, ya que el "impulso primigenio de lo poético [...] no es otro que el hechizo de la fisicalidad del 
mundo"8 (2004: 430-431). La palabra poética es para Sánchez Robayna, en fin, "una convocación de la presencia", "la experiencia de lo sagrado". Esta experiencia está íntimamente ligada a un "sentimiento del lugar" como consciencia de formar un "todo con la tierra" (2004: 432-433): en el caso de Robayna, responde a lo largo de toda su obra a la idea de insularidad, inspirada en Lezama Lima, a partir de la vivencia de las Islas Canarias como "lugar otro, ajeno al devenir histórico [...] en la que todavía es posible «el encuentro del hombre con una verdad de la imaginación»" (Fernández Casanova, 2005: 135).

Si bien la experiencia transcendente en o a través del paisaje, como hemos comprobado, está en la poesía del escritor canario desde el principio, a partir de 1989, con la publicación de Palmas sobre la losa fría, esta experiencia toma un cariz mucho más claramente sagrado, místico. Sus textos se vuelven más discursivos, narrativos, con una mayor presencia del yo, diríase que más "convencionales". Una vez superada su obsesión lingüística, Robayna opta por un lenguaje "religioso", o, mejor dicho, una concepción religiosa del lenguaje, tal y como la concibe, principalmente, en el artículo arriba citado.

En efecto, en Palmas sobre la losa fría, se observa un viraje hacia una experiencia mística que, si bien estaba latente en libros anteriores, aparece aquí en un sentido más apegado a la "tradición", ya desde la cita que encabeza el conjunto, sustituyendo a Góngora y Mallarmé por San Juan de la Cruz ${ }^{9}$. Ni los temas ni el paisaje cambian, pero aparecen "habitados" por el yo y el tiempo - y la muerte ${ }^{10}$. Esta tendencia a lo narrativo y a la experiencia religiosa se puede comprobar nítidamente en "Luz de Fuerteventura" [Palmas sobre la losa fría, 202-206], que narra el paseo de un "nosotros" por la isla que pronto se transfigura en viaje místico. El paisaje, descrito de forma "realista", aparece transido de una simbología y unos giros típicamente místicos ("Caminamos. / Entramos a otra luz, a otro silencio”; “¿Fue el sueño de una tierra herida, luz / disipada de pronto para ver / tras la luz el sentido de la luz?"), y hacia el final del

8. La idea del poeta enamorado de las cosas del mundo, de todas y cada una de las apariencias de la realidad, a diferencia del filósofo, que ansía la unidad abstracta del Ser, la teoriza Zambrano en su Filosofía y poesía, de 1939

9. Para la relación de Sánchez Robayna con la mística, véase Castro (1989-1990).

10. "La presencia de la muerte, la certeza del acabamiento, abre esta nueva forma poética ya en Palmas sobre la losa fría. La entrada del yo en el poema sintetiza la conciencia de la temporalidad sobre los elementos vistos, leídos, escritos" (Ruiz Casanova, 2011: 42). 
texto el yo que es un nosotros se siente identificado con él y la presencia trascendente que lo habita:

¿No somos hijos de la sal, no somos tuyos, no somos tú?

[...] dinos,

antes de que renazca

el sol sobre la tierra recortada

en este mar que brilla en la noche mortal, quiénes somos, quién eres, imagen respirante, qué palabra nos dice tu sueño o tu verdad.

La tendencia se acentúa en el siguiente libro, Fuego blanco, cuyo título alude a la tradición cabalística según la cual la Tora fue escrita en "fuego blanco", ilegible, y más tarde traducida en "fuego negro" (Terry, 2000: 111). El poemario está atravesado por los motivos de la llama y el incendio como símbolos de la iluminación trascendente: "En la llama morir, y renacer / en otra convocada llama viva" ["Signo, vacío", Fuego blanco, 263].

\section{RETÓRICA DE LO SAGRADO}

\subsection{Teoría del símbolo y la alegoría}

Acabamos de mencionar el símbolo y es conveniente detenerse en este término, pues la clave de lo que resta de argumentación está, como hemos adelantado al comienzo, en el paso de un lenguaje "metalingüístico" a un lenguaje simbólico. Y hablar del símbolo es inevitablemente hablar de la teoría romántica y su oposición frente a la alegoría. Es Goethe el primero que revaloriza el símbolo y lo opone a la alegoría: mientras que en esta, como en toda figura retórica (según la tropología clásica, como ya sabemos), el significante, la forma alegórica, es omitido una vez que se ha llegado al conocimiento alegorizado, el símbolo significa intransitivamente: "ante todo se presenta por sí mismo y sólo en un segundo momento descubre además lo que significa" (Todorov, 1981: 282); si ambos comparten la característica de significar algo general a partir de un caso particular, el símbolo significa por una motivación connatural, lo general está encarnado en lo particular, "como una epifanía inmediatamente perceptible”, mientras 
que la significación alegórica resulta de una operación racional, artificial y conceptual (Cuesta Abad, 1997: 34). Gadamer asigna al símbolo romántico un contenido metafísico, y a la alegoría una forma retórica (Cuesta Abad, 1997: 34), considera que la valoración romántica del símbolo coincide con la no distinción entre la experiencia y su representación: "el lenguaje poético del símbolo, propone Gadamer, es capaz de trascender esta distinción, y de transformar así toda experiencia individual directamente en una verdad general" (De Man, 1991: 208).

Mientras que el símbolo para la teoría romántica y post-romántica es "productor, intransitivo, motivado; logra la fusión de los contrarios: es y a la vez significa, su contenido escapa a la razón: expresa lo indecible" (Todorov, 1981: 287), la imagen alegórica "no significa [...] una superación, sino una consagración del abismo entre el reflejo sensible humano de la realidad y el reflejo conceptual y desantropomorfizador" (Lukács, cit. en Cuesta Abad, 1997: 35).

Para Hegel, el símbolo es un tipo de signo en cuya dimensión sensible "incluye en sí el contenido de aquello que representa, pero por otro lado, el contenido simbolizado sobrepasa con creces la capacidad significante del símbolo, y este debe "seleccionar [...] un contenido entre una multiplicidad de sentidos que son también intuitivamente relevantes", de ahí su ambigüedad y el aparente carácter inagotable de sus significaciones (Cuesta Abad, 1997: 36; también Eco, 1990: 256).

Frente a la devaluación romántica de la alegoría a favor del símbolo, hay autores como Walter Benjamin o Paul De Man que reivindican su importancia. Para este último, la alegoría aparece en los momentos "más originales y profundos" del Romanticismo (De Man, 1990: 227). Según De Man, la alegoría tiene que ver con la conciencia de la temporalidad, de la que el yo romántico buscaba protegerse, símbolo mediante, refugiándose en una unión imposible con la naturaleza. Si el símbolo es fundamentalmente espacial, pues forma y contenido coinciden en una sinécdoque en la que la parte encarna al todo, en la alegoría el referente deja de tener importancia, y el signo alegórico remite a un signo que le precede temporalmente y con quien por tanto no puede ser completamente identificado. La alegoría revela la distancia temporal entre el yo y un no-yo; la predominancia declarada del símbolo no constituye sino una automistificación de esta verdad (De Man, 1990: 229-231) - "si el símbolo postula la posibilidad de una identidad o una identificación, la alegoría marca ante todo una 
distancia respecto de su propio origen" (1990: 230).

Cuesta Abad, por su parte, considera que la demostración de De Man, si bien sus conclusiones son totalmente aceptables, es innecesaria, pues "pasa por alto [...] que las contradicciones internas del lenguaje poético romántico dependen en buena medida del hecho de que [...] el símbolo romántico, lejos de emerger como forma especial de expresión, no tiene otra existencia que la de un contenido tematizado por el lenguaje teórico o poético" (Cuesta Abad, 1997: 41). Además, para el teórico español es dudosa la distinción entre la naturaleza espacial del símbolo y la temporal de la alegoría: esta cualidad temporal sólo puede determinarse históricamente como significado ideológico, pero teóricamente, la distancia entre un signo y su significado es común a toda semiosis, y podría expresarse perfectamente en términos espaciales, o incluso como posterioridad en lugar de anterioridad (1997: 42).

En todo caso, para este autor, la distinción entre símbolo y alegoría es, desde un punto de vista metarretórico, imposible: la única posibilidad de definir teóricamente el símbolo es atribuirle las características generales de toda expresión figurada, aunque se pueda precisar alguna peculiaridad, como que el símbolo da lugar a una interpretación connotativa ilimitada o que constituya "una nebulosa de significados alegóricos que tienden a ramificarse dinámicamente por efecto de la interpretación" (Cuesta Abad, 1997: 39). Alegoría y símbolo "no se distinguen, pues, por la naturaleza lógica de la relación entre simbolizante y simbolizado, sino a partir del modo de evocación de lo general por lo particular" que se decide siempre en el momento de la interpretación (Todorov, 1981: 286-287).

Para terminar, conviene tener presente una consideración que va a ser clave en la argumentación que nos resta. Para Hegel, lo simbólico no es lo artístico sino su origen, y por tanto algo distinto: "lo simbólico nace como pre-arte cuando el hombre vislumbra en los objetos naturales (pero no se trata de una identidad absoluta) el sentimiento superior de algo universal y esencial" (Hegel, cit. en Eco, 1990: 256) que es lo que se expresa en el texto. Le Guern basa su distinción entre metáfora y símbolo en que este es un fenómeno extra-textual: no es la palabra lo importante en la significación del símbolo, sino la representación mental a que esta designa, "la palabra misma no es más que la traducción en el lenguaje de una relación extralingüística" (Le Guern, 1980: 45-46), mientras que la metáfora afecta a la misma estructura sémica. También Eco destaca que la 
metáfora no se puede interpretar literalmente, pero el símbolo puede ser leído sin atender a su sentido indirecto, y en todo caso viola la máxima de pertinencia para señalar que dice algo más de lo que parece decir (Eco, 1990: 282). El símbolo, por así decirlo, es transparente en tanto que remite directamente a la realidad simbólica sin que su materialidad sea importante, no así en el caso de la metáfora, que juega directamente con el sistema lingüístico.

\title{
4.2. Sobre una piedra extrema: la alegorización del símbolo
}

Volvamos ahora a la poesía de Sánchez Robayna y ocupémonos del último poemario de esta etapa, Sobre una piedra extrema. En rasgos generales, la temática del libro gira en torno a la permanencia y la impermanencia: un yo adulto regresa a parajes del pasado (y de hecho ciertos pasajes pueden ser leídos metapoéticamente, como refiriéndose a su anterior poesía $\mathrm{a}^{11}$ ), preferentemente de la infancia, donde una higuera o un volcán pueden simbolizar el paso del tiempo: tanto lo que permanece a pesar de él, como lo que desaparece ${ }^{12}$. Recordemos que, para Ruiz Casanova, lo definitorio de esta etapa de la poesía de Robayna es la aparición del Yo, y por tanto de la temporalidad y con ella la Muerte.

Podemos considerar este libro como la culminación de este proceso de cambio en que se abandona la experimentación lingüística y metalingüística en beneficio de una expresión más directa y desnuda. La metáfora del mundo como texto seguirá operativa, presente también en algunas expresiones metafóricas en que los elementos naturales son signos, pero ya no son entendidos en su forma radical significante sino, precisamente, como símbolos:

\author{
El ramaje extendido, \\ la hierba, como un afloramiento
}

11. Por ejemplo: “LLengua, lenguaje, / digo? ¿Una palabra / más allá del lenguaje, eso buscaba? // Solamente más tarde iba a saberlo, cuando el lenguaje habló, y tan sólo / llegó el lenguaje a ser la destrucción / de cuanto conocía. Y era, al mismo tiempo, / la construcción de todo. Yo volvía / otra vez a los árboles, aún / no sabía del lenguaje sino sólo su enigma" ["Más allá de los árboles", 307]

12. Para una exploración más detallada del pensamiento poético del autor durante esta etapa que empieza con Palmas... y culmina con Sobre una piedra extrema, y un análisis de las nociones de temporalidad, memoria, religiosidad, etc., así como otro comentario acerca del poema "Sobre una piedra extrema", que estudiaremos más adelante, véase el artículo ya citado de Fernández Casanova (2005). 
del interior del mundo, las raices

de lo visible, los arbustos, el aire, eran una llamada del lenguaje. Y eran

una llamada de más allá de él, como si aquella luz hablara de otro mundo, siendo el mundo mismo ["Más allá de los árboles", 307].

Quizá la teoría del símbolo antes expuesta arroje una nueva perspectiva a esta tendencia a la dicción "realista", muchas veces autobiográfica, que encontramos en esta etapa, como queda ejemplificado en poemas como "La tarde de verano", "La higuera", u "Obediencia - El volcán":

Caminas, sí, son las seis de la tarde, la hora de la pintura, el sol da en la fachada de una iglesia, caminas junto a Ramon Xirau, el tiempo gira en las palabras que dialogan, la luz, madura, entra en el templo.

Hace ya muchos años que estuviste

bajo esta luz quemada, en este mismo sitio [...] [“Obediencia - El volcán”, 314].

En efecto, una vez que la realidad se comprende no como signo sino como símbolo, la cualidad sagrada, simbólica, de la palabra se da en cuanto que remite a una imagen extratextual, no a su dimensión lingüística, y por tanto basta con designar esas realidades, la luz, las hojas, el volcán, que son las que configuran la trama simbólica del libro. Esto es: si en el ciclo anterior la palabra y su materialidad como tal tenía una importancia central, ahora la tiene la realidad, que es simbólica en sí misma, a la que la palabra apunta.

Detengámonos en el largo poema que da título al libro, "Sobre una piedra extrema" [328-334], y que es versión de un poema recogido en Fuego blanco, "Una piedra, memoria" [269-270]. Ambos narran una experiencia infantil del poeta: un niño, durante un paseo al atardecer, graba su nombre en una piedra. Pronto la narración de "Sobre una piedra extrema" se revela alegórica: el tema del poema es el descubrimiento de la muerte, 
vista en la sombra que progresivamente la montaña va proyectando sobre los sembrados que el niño recorre ("Pensé tal vez, bajo aquel sol, que el cielo / iba a cubrir de pronto los sembrados / y la luz a abolirse"), y de la escritura como maniobra de defensa contra la muerte, lo "impermanente" ("una inscripción / sobre la piedra, nunca arrebatable / por la muerte"). La paradoja nuclear del poema, fiel a la imagen mallarmeana de la obra poética como tumba de su autor, es que este acto de escribir para salvaguardar la propia identidad contra el paso del tiempo es precisamente lo que da lugar a esa misma conciencia temporal:

\author{
¿Comenzaba allí un libro? \\ ¿O es que era, lo que llamo comenzar, \\ la conciencia primera \\ del fin, una inscripción contra la muerte \\ de la luz?
}

Este sentido elegíaco de la escritura queda explicado por Robayna en "Deseo, imagen, lugar de la palabra":

¿No es todo poema, en verdad -me he preguntado alguna
vez-, una elegía? ¿No representa un canto que es capaz
de decir, y de decirse, aun en la más cerrada conciencia
de la muerte, y precisamente por ella? [...] Pues incluso
un poema de celebración [...] es poema de celebración de
la vida, y lo que se sitúa frente a la vida con su misma
energía y plenitud es la conciencia de su pérdida (Sánchez
Robayna, 2004: 433).

La narración se alterna con otros fragmentos que contienen unos desarrollos metafóricos, además de las parejas luz/sombra, vida/muerte, comienzo/fin, que constituyen una teoría de la escritura, de "lo visible". El poeta ya no se propone escribir lo invisible, sino lo visible, lo que termina, y cuya inscripción pretende desafiar a la muerte - la piedra, evidentemente, es idónea porque es un objeto permanente: "La piedra / era el aire y el agua hechos materia/ capaz de recibir una inscripción, / [...] Son el mundo, / como la piedra duraderos, / como el ser de la piedra/ que un nombre graba, y asi escribe el mundo". Pero lo "visible" no sólo se da con la 
luz ("no se produce / lo visible sin luz, aunque la luz no baste"), sino también con su término ("no se produce lo visible / sin término"), ya que, en un sentido perceptivo, y directamente relacionado con la argumentación desarrollada más arriba, el límite entre la luz y la sombra es lo que da forma a los objetos.

Todas las intuiciones semióticas trabajadas por Sánchez Robayna en su primera etapa acerca de la significación, la huella, la sombra, la delimitación, la delineación de la forma, en fin, la escritura de la realidad, se reúnen en este poema y se vinculan con la experiencia de la muerte. De esta manera, en la imagen de lo visible como resultado de la luz y su término, en el gesto de inscripción en la piedra, se encuentran magistralmente la experiencia y la escritura ("La inscripción era acaso un testimonio / de lo visible que iba hasta su término, / hacia la muerte"), lo real y lo trascendente ("testimonio de los mundos"), el despertar del yo ("el alma que escuchaba y despertaba / en un nuevo nacer de ver y oír") a la conciencia de la vida y la muerte. No se escribe sino lo visible, y lo visible es lo que termina. Sólo este descubrimiento da paso a la escritura.

Ahora bien, si la escritura es el tema central de este poema ¿qué más se nos dice en el poema sobre ella? Nos encontramos con la conciencia de una distancia fundamental entre la escritura y la experiencia expresada por la escritura: entre la materia del aire y el agua, y la materia de la piedra, entre la piedra (la escritura) y la carne (el yo):

\section{¿La piedra se atormenta como la carne? Pudo parecerme que un estremecimiento la cruzaba, o era sólo la mano sobre el borde que contagió a la piedra su temblor.}

El autor duda constantemente de la validez de sus afirmaciones ("Era, tal vez, rasgar, tocar la entraña de los mundos"; "Fue, tal vez, la memoria de los mundos"; "Pensé tal vez, bajo aquel sol, que el cielo..." "me pareció decir / una palabra, acaso, contra lo impermanente"; "No sabría decir si me pregunto sólo / por el sentido"): la escritura es, fundamentalmente, pregunta ("me pregunté, al volver / a la casa, de noche, por el signo / de la tarde y la piedra"; "como si sólo la pregunta fuera/ la casa que habitamos"), y es la forma que toma el poema: “¿La piedra 
se atormenta...?”; “Comenzaba allí un libro?”... Las únicas aserciones fuertes son, de hecho, las que hablan sobre las condiciones de lo visible (no se produce lo visible sin luz, sin término, sin distancia, etc.): lo único seguro es la muerte.

El poema nos ofrece, por tanto, una reflexión de la escritura, esta escritura que se erige contra la experiencia de la muerte, como una escritura alegórica. El poema es claramente una alegoría: se nos ofrece una imagen, un relato, y el resto del texto consiste en la posible interpretación de este. El autor, como vemos, duda constantemente acerca de la significación de su propio relato, esto es, de su propia interpretación alegórica, no porque el lenguaje simbólico suscite infinitas interpretaciones, sino porque el significado alegórico viene dado por el propio yo: no es una duda metafísica, sino acerca de la propia escritura. Es en el mismo comienzo donde se nos declara la naturaleza narrativa del poema, y la precariedad del relato, configurado por la propia memoria:

Como una mano que protege, cóncava,

la llama de una vela contra el viento, en lo oscuro, la memoria

guarda una piedra, cifra del origen.

Quizá el mecanismo retórico que aquí más nos interesa sea el del símil, como el que vemos en estos versos. A diferencia de la metáfora, el símil no llega a expresar la identidad entre los dos términos, de modo que la violencia lingüística o cognitiva (u ontológica, si queremos) no es tanta, al mantener siempre la distancia entre ambos. La memoria no es una mano protegiendo una vela, sino que actúa como tal. Encontramos la comparación por todo el poema ("Al pie de la ladera, los mundos reunidos, como los une un libro"; "Son el mundo, / como la piedra duraderos, / como el ser de la piedra"; Y la pregunta / dura a través de toda duración, / como si sólo la pregunta fuera...”) y, en general, es muy abundante en todo el libro. El símil, decimos, no expresa una identidad, deja claro que esta comparación no es necesaria ni natural, sino que ha sido establecida por el mismo sujeto - es su lectura (escritura) de la realidad. Si en su primera etapa, como veíamos, Sánchez Robayna proponía una identidad (metafórica) de la realidad con el texto (la producía, como argumentábamos), en esta etapa se muestra más cauto respecto de estas transformaciones tropológicas. 
Analicemos un último poema de Sobre una piedra extrema, más breve: "Aquí y ahora, en este mismo instante" [317], donde lo que se expresa es un momento de experiencia de lo transcendente propiciado por la entrada de la luz del sol en la habitación donde el yo escribe. Este sentimiento viene temporalmente caracterizado por su mínima brevedad; la inmediatez de "el solo instante / que encarna el instante" es tal que en su mínima extensión es capaz de contener "la gravedad del cielo" recordemos las palabras de Valente acerca del "decir más corto que aloja el significado más inabarcable".

El texto está determinado por la quietud en que se produce la visión, que se refleja no sólo en la dicción sino en las mismas imágenes y predicaciones utilizadas ("el alimento pobre", "la luz vertical", "algo, sí, tan simple"; la luz que "reposaba como / en una paz"; "el cielo desnudo"). La sencillez y contención de la composición ni siquiera se ve perturbada por las expresiones paradójicas que refieren a la experiencia trascendente ("una luz / casi de amanecer que de sí misma / brotaba"); expresiones que, por otra parte, vienen de una sólida tradición filosófica y literaria. Las imágenes naturales que acompañan e ilustran esta experiencia vienen a colaborar la facilidad con la que se da la visión y se es capaz de transmitirla.

Y sin embargo, encontramos aquí las mismas conclusiones sobre la escritura que habíamos obtenido del poema anterior, si bien en este caso implícitas y sin que se tematice la duda. En efecto, la visión se produce en un instante, pero la figuralidad marca una distancia entre la experiencia y su escritura, enunciada ya en el contraste entre el título ("Aquí y ahora, en este mismo instante") y el primer verso ("Hace sólo un momento..."). Las mismas paradojas que expresan la trascendencia dan cuenta de una distancia entre el amanecer y la luz que es casi el amanecer, entre la simpleza de la escena y la transcendencia que "sin embargo" encarna; distancia duplicada en la misma imagen alegórica del estanque de juncos, en una lejanía que un pájaro tiene que recorrer para traer "aquí" los juncos. La imagen que aparece en la primera estrofa ("el modo en que la cría del pájaro / levanta el cuello para recibir / el alimento pobre") parece recuperar procedimientos arriba estudiados al reducir el gesto del animal a su pura "verticalidad en sí misma". Y, sobre todo, la misma figuración, centrada en el "como" que hila el poema ("tan simple como el modo en que la cría"; "reposaba como / en una paz", “como / juncos en un estanque"; "dejar, como en su nido"), reforzado por el uso del modo subjuntivo, viene a trasladar esta distancia a 
la misma escritura, marcando el recorrido que el lector ha de hacer desde un término a otro de la comparación. El poema, en fin, es un relato de la experiencia simbólica que el sujeto tiene del mundo, pero él mismo marca una distancia entre la experiencia de la trascendencia y su escritura

\section{CONCLUSIONES}

El objeto que ha recorrido esta investigación ha sido el análisis del uso del lenguaje de Sánchez Robayna; cómo se confrontaba el pensamiento poético del autor canario acerca de la palabra como lugar e instrumento de la experiencia de lo sagrado con la retórica del poema.

Respecto a la primera etapa de su producción, la que comprende los libros Clima, Tinta y La roca, hemos comprobado cómo la metáfora que domina estos poemas, la del mundo como texto, lleva al poeta a una experimentación metalingüística acerca de la naturaleza del signo. La recreación del misterio insular se vuelve un pretexto para investigar la producción semiótica: la mirada del poeta se centra en las huellas, las sombras, los contornos que producen los objetos al darles forma; la atención a la materialidad del signo reduce el paisaje a un juego de significantes. Como resultado, la única realidad que se convoca en el poema es la del texto.

La práctica poética del autor da un giro a partir de Palmas sobre la losa fría, dejando de lado la experimentación formal en favor de una concepción simbólica de la realidad y el lenguaje. La realidad pasa a entenderse no como signo, como significante, sino como símbolo, como imagen que remite a un contenido trascendente. Pero se mantiene la investigación acerca del papel del lenguaje en la experiencia de lo sagrado. Confrontando las categorías de símbolo y alegoría y su uso en los poemas de Sobre una piedra extrema, así como de otros tropos como el símil, llegamos a la conclusión de que en estos textos la experiencia sagrada se da fuera del lenguaje, y el poema sólo da cuenta de él a posteriori. El poema expulsa del lenguaje la experiencia sagrada para remitirla a un espacio extra-textual.

La escritura para Sánchez Robayna, entonces, consiste en intentar transcribir e interpretar, alegóricamente, una experiencia sagrada, trascendente, que sucede fuera del poema; y esta escritura/interpretación resulta siempre insuficiente, inexacta. Nuestra lectura demuestra cómo la 
poesía del autor canario tematiza alegóricamente una concepción simbólica de la relación del yo con el mundo a la vez que muestra el insalvable trecho que hay entre la experiencia de este vínculo y el lenguaje que lo relata; traslada la experiencia simbólica a la naturaleza mientras que reserva al lenguaje su naturaleza alegórica al marcar la distancia entre el signo y el significado que le sigue o precede pero nunca coincide con él.

\section{REFERENCIAS BIBLIOGRÁFICAS}

AMORÓS, A. (1982). "La retórica del silencio”. Los Cuadernos del Norte $16,18-28$.

(1992). La palabra del silencio (La función del silencio en la poesía española a partir de 1969). Madrid: Servicio de Reprografía de la Universidad Complutense de Madrid.

CASTRO, F. (1989-1990). "La luz que nombra". Revista de Filología de La Universidad de La Laguna 8-9, 89-99.

CUESTA ABAD, J. M. (1997). Las formas del sentido. Estudios de Poética y Hermenéutica. Madrid: Servicio de Publicaciones de la Universidad Autónoma de Madrid.

DE MAN, P. (1991). Visión y ceguera: ensayos sobre la retórica de la crítica contemporánea. Puerto Rico: Universidad de Puerto Rico.

DOMÍNGUEZ REY, A. (1985). "Luz y mirada en la poesía de Andrés Sánchez Robayna". Ínsula 462, 5-6.

ECO, U. (1990). Semiótica y filosofía del lenguaje. Barcelona: Lumen.

FERNÁNDEZ CASANOVA, M. (2005). "Sentidos que no sé": El pensamiento poético de Andrés Sánchez Robayna". Revista Hispánica Moderna 58, 135-158.

JIMÉNEZ ARRIBAS, C. (2004). "Lectura del mundo como texto: el poema en prosa en Tinta de Andrés Sánchez Robayna”. En El poema en prosa en los años setenta en España (tesis doctoral). UNED.

LE GUERN, M. (1980). La metáfora y la metonimia. Madrid: Cátedra.

LÓPEZ FERNÁNDEZ, L. (2000). "El esencialismo en la poesía de Andrés Sánchez Robayna”. Anales de Literatura Española Contemporánea, 25(1), 171-191.

MATA BUIL, A. (2014). “'Latiendo sobre el ojo que escucha la tinta': 
Andrés Sánchez Robayna y el poema en prosa". Anuario de Estudios Atlánticos 60, 733-795.

RODRÍGUEZ PADRÓN, J. (1979). “Andrés Sánchez Robayna: la palabra insular”. Ínsula 392-393, 1 y 24.

(1981). "Andrés Sánchez Robayna: la escritura como experiencia". Ínsula 421, 3 y 5.

RUIZ CASANOVA, F. R. (2011). "Introducción". En El espejo de tinta (antología 1970-2010). Madrid: Cátedra.

SÁNCHEZ ROBAYNA, A. (1985). La luz negra. Barcelona: Júcar. (1993). Silva gongorina. Madrid: Cátedra. (2004). En el cuerpo del mundo. Barcelona: Galaxia Gutenberg.

TERRY, A. (2000). "Andrés Sánchez Robayna o la palabra y el signo" En La idea del lenguaje en la poesía española. Crespo, Sánchez Robayna y Valente, 85-117. Santiago de Compostela: Universidad de Santiago.

TODOROV, T. (1981). Teorías del símbolo. Caracas: Monte Ávila.

VILLENA, L.A. de. (2000). Teorías y poetas. Panorama de una generación completa en la última poesía española. Valencia: Pre-Textos.

Recibido el 13 de mayo de 2017.

Aceptado el 3 de septiembre de 2017. 
